\title{
Lactobacillus paracasei NFRI 7415 Reduces Liver Lipid Contents in C57BL/6J Mice Fed a High-fat Diet
}

\author{
Noriko Komatsuzaki ${ }^{*}$, Yumiko Yamada ${ }^{2}$, Yukihide Ueki ${ }^{1}$, Jun Shima ${ }^{3}$ and Shunichi Morikawa ${ }^{4}$ \\ ${ }^{1}$ Department of Human Nutrition, Seitoku University, 550 Iwase, Matsudo, Chiba 271-8555, Japan \\ ${ }^{2}$ Nodakamada Gakuen, 389-1 Noda, Noda, Chiba 278-0037, Japan \\ ${ }^{3}$ Faculty of Agriculture, Ryukoku University, 1-5 Yokotani, Seta Oe-cho, Otsu, Shiga 520-2194, Japan \\ ${ }^{4}$ Department of Anatomy and Developmental Biology, Tokyo Women's Medical University, 8-1 Kawada-Cho, Shinjuku, Tokyo 162-8666, Japan
}

\begin{abstract}
We examined the effects of Lactobacillus paracasei NFRI 7415 isolated from Japanese fermented fish (funa-sushi) on the whole-body and fat-tissue weights, plasma lipid concentration and hepatic lipid contents of mice. Male C57BL/6J mice were fed a control diet (CD), high-fat diet (HD) or HD containing Lb. paracasei NFRI $7415\left(10^{6} \mathrm{cfu} / \mathrm{g}\right)$ (HLD) for 10 weeks. The plasma triacylglycerol concentration of the HLD group was lower than that of the HD group. The plasma glucose, leptin and hepatic lipid concentration of the CD and LHD groups were lower than those of the HD group. As a result of measuring the liver lipids and the liver histology, it was observed that the number of lipid droplets in liver cells in the HD group was clearly greater than that in the CD and HLD groups. The total liver lipids in the CD and HLD group were lower than that of the HD group. This suggests that intake of Lb. paracasei NFRI 7415 is effective in overcoming the effects of HD to prevent hepatic lipid accumulation.
\end{abstract}

\section{Publication History:}

Received: April 17, 2016

Accepted: June 16, 2016

Published: June 18, 2016

\section{Keywords:}

Lactobacillus paracasei, high-fat diet, liver lipid, mice, probiotics

\section{Introduction}

In recent years, the increase in obesity and diabetes with the westernization of eating habits in Japan has become an important factor in the development of arteriosclerosis and cerebrovascular diseases $[1,2]$. According to the national health and nutrition survey of 2013 [3], 28.6\% of men and $20.3 \%$ of women over 20 years old were obese (BMI $\geqq 25$ ). Obesity is one of the major risk factors of coronary heart disease, arteriosclerosis, fatty liver, diabetes B, hypertension and various other diseases [4]. Improving diet is effective for the prevention of lifestyle- related diseases. Functional foods and supplements have received a good deal of attention in this context [5].

Lactic acid bacteria (LAB) have been utilized as a natural health food from ancient times, and the health-promoting effects of LAB are well recognized [6]. Some Lactobacillus strains are used in food fermentation, and typical examples are found in the dairy industry for the production of cheese, yogurt, and other fermented milk products $[2,7]$. Recent studies have indicated that several Lactobacillus strains are effective for the prevention of obesity as probiotics. For example, Lactobacillus plantarum and Lactobacillus gasseri may exert a beneficial effect on the onset of diet-induced obesity by reducing the cell size of white adipose tissues [8,9]. Andersson et al. [10] indicate that Lactobacillus plantarum DSM 15313 has anti-diabetic properties in the context of a high-fat diet.

We reported that Lactobacillus paracasei NFRI 7415 isolated from traditional Japanese fermented fish (funa-sushi) showed high $\gamma$-aminobutyric acid (GABA)-producing ability [11]. GABA has several well-known physiological functions, including neurotransmission, induction of hypotensivity, a diuretic effect, and tranquilizer effects $[12,13]$. Although we found that $L b$. paracasei NFRI 7415 is used in the development of functional fermented foods, this phenomenon has not yet been studied in vivo in humans and animals. Our previous study suggests that $L b$. paracasei NFRI 7415 is beneficial for improving liver damage due to chronic alcohol intake, [14] but to our knowledge no effect of $L b$. paracasei in the prevention of obesity has been reported.
We speculated that $L b$. paracasei NFRI 7415 may have improved liver function in the above-mentioned clinical study by somehow reducing hepatic lipid contents. In the present study, we focused on the effect of LAB consumption on obesity, assuming that it would change the lipid metabolism. We investigated body and fat tissue weights, the plasma lipid concentration and hepatic lipid contents in a high-fat diet (HD)fed C57BL/6J mice.

\section{Materials and Methods}

Preparation of extract: A pre-culture of $L b$. paracasei NFRI 7415 was grown to the stationary phase at $37^{\circ} \mathrm{C}$ for $20 \mathrm{~h}$ in MRS (Difco Laboratories, Detroit, MI) medium. The medium was prepared by mixing a high-fat diet (HD) and sterilized water at a ratio of 1 to 3 . The pre-cultures $\left(10^{6} \mathrm{cfu} / \mathrm{g}\right)$ were inoculated in the $\mathrm{HD}$ at $37^{\circ} \mathrm{C}$ for 48 $\mathrm{h}$. The medium was immediately freeze-dried and used in the animal experiments.

Animals and diets: Eighteen 5-week-old C57BL/6J mice were purchased from Charles River Japan (Yokohama, Japan). All the animals were housed individually in plastic cages in a controlled environment of $22 \pm 1^{\circ} \mathrm{C}$ at $50 \%$ relative humidity under a 12-h dark/ light cycle (19:00-7:00). The animals were randomly divided into three dietary treatment groups with equal mean body weight: the control diet $(\mathrm{CD})$ group $(\mathrm{n}=6)$, the HD group $(\mathrm{n}=6)$, and the freezedried medium with $L b$. paracasei NFRI $7415(106 \mathrm{cfu} / \mathrm{g})$ and HD blended at a ratio of 1 to $4(\mathrm{HLD})$ group $(\mathrm{n}=6)$. The HLD contained approximately $100 \mathrm{mg} / \mathrm{kg}$ of live $L b$. paracasei NFRI 7415, as in other studies. The composition of the diets (CD, HD, and HLD), shown in Table 1 was based on the AIN-93G diet [15]. HD and HLD were

"Corresponding Author: Dr. Noriko Komatsuzaki, Department of Human Nutrition, Seitoku University, 550 Iwase, Matsudo, Chiba 271-8555, Japan, Fax: +81-47-363-1401; E-mail: norikoma@seitoku.ac.jp

Citation: Komatsuzaki N, Yamada Y, Ueki Y, Shima J, Morikawa S (2016) Lactobacillus paracasei NFRI 7415 Reduces Liver Lipid Contents in C57BL/6J Mice Fed a High-fat Diet. Int J Clin Nutr Diet 2: 108. doi: http://dx.doi.org/10.15344/ ijcnd/2016/108

Copyright: @ 2016 Komatsuzaki et al. This is an open-access article distributed under the terms of the Creative Commons Attribution License, which permits unrestricted use, distribution, and reproduction in any medium, provided the original author and source are credited. 
Citation: Komatsuzaki N, Yamada Y, Ueki Y, Shima J, Morikawa S (2016) Lactobacillus paracasei NFRI 7415 Reduces Liver Lipid Contents in C57BL/6J Mice Fed a High-fat Diet. Int J Clin Nutr Diet 2: 108. doi: http://dx.doi.org/10.15344/ijcnd/2016/108

Page 2 of 5

Table 1: Compositions of the Experimental Diets.

\begin{tabular}{|l|l|l|l|}
\hline Ingredient & $\mathrm{CD}^{1}$ & $\mathrm{HD}^{2}$ & $\mathrm{HLD}^{3}$ \\
\hline Casein & 20.0 & 20.0 & 20.0 \\
\hline L-Cystine & 0.3 & 0.3 & 0.3 \\
Cornstarch & 55.4 & 24.9 & 24.9 \\
Sucrose & 10.0 & 10.0 & 10.0 \\
Soybean oil & 4.5 & 4.5 & 4.5 \\
Lard & - & 30.5 & 30.5 \\
Cellulose & 5.0 & 5.0 & 5.0 \\
Mineral mixture & 3.5 & 3.5 & 3.5 \\
Vitamin mixture & 1.0 & 1.0 & 1.0 \\
Choline bitartrate & 0.25 & 0.25 & 0.25 \\
tert-Butylhydroquinone & 0.0014 & 0.0014 & $0.0014\left(10^{6} \mathrm{cfu} / \mathrm{g}\right)$ \\
Lb. paracasei extract & - & - & \\
\hline Energy (kcal/g) & 3.6 & 5.2 & 5.2 \\
Protein energy ratio (\%) & 22.5 & 15.3 & 15.3 \\
Fat energy ratio (\%) & 11.4 & 60.4 & 60.4 \\
Carbohydrate energy ratio (\%) & 66.1 & 24.3 & 24.3 \\
\hline
\end{tabular}

${ }^{1} \mathrm{CD}$ : control diet; ${ }^{2} \mathrm{HD}$ : high-fat diet; ${ }^{3} \mathrm{HLD}$ : Lb. paracasei containing high-fat diet

${ }^{4}$ Mineral mixture (g/kg of mix): $\mathrm{CaHPO}_{4}, 500.0 ; \mathrm{NaCl}, 74.0 ; \mathrm{K}_{3} \mathrm{C}_{6} \mathrm{H}_{5} \mathrm{O}_{-}$ $\mathrm{H}_{2} \mathrm{O}, 220.0 ; \mathrm{K}_{2} \mathrm{SO}_{4}, 52.0 ; \mathrm{MGO}, 24.0 ; \mathrm{MnSO}_{4} 5 \mathrm{H}_{2} \mathrm{O}, 6.77 ; \mathrm{FeSO}_{4} \cdot 7 \mathrm{H}_{2} \mathrm{O}$, 4.95; $\mathrm{ZnCO}_{3}, 1.6 ; \mathrm{CuCO}_{3} \mathrm{Cu}(\mathrm{OH})_{2} \mathrm{H}_{2} \mathrm{O}, 0.3 ; \mathrm{KlO}_{3}, 0.01 ; \mathrm{NaSeO}_{3}, 0.01 ;$ $\mathrm{CrK}\left(\mathrm{SO}_{4}\right)_{2} \cdot 12 \mathrm{H}_{2} \mathrm{O}, 0.55 ; \mathrm{NaF}$, 0.06; Sucrose, 115.75 .

5 Vitamin mixture ( $\mathrm{g} / \mathrm{kg}$ of mix): retinol, 4.8 ; cholecalciferol, 0.4 ; thiamine, 24.0; riboflavin, 0.6 ; pantothenic acid, 0.6 ; pyridoxine, 0.7 ; cobalamin, 0.01; menadione, 0.05 ; nicotinic acid, 3.0; D-calcium pantothenic acid, 1.6; folic acid, 0.2; biotin, 0.02; para-aminobenzoic acid, 5.0; inositol, 10.0; glucose, 949.02 .

prepared by adding lard (30.5\%) to the AIN-93G, respectively, and substituting cornstarch. The mice were fed the CD, HD, or HLD for 10 weeks. Food intake was recorded daily, and body weight was measured on alternate days. After the feeding period, the mice were fasted for $16 \mathrm{~h}$ and sacrificed humanely under ether anesthesia to collect the liver and perirenal fat tissue. The blood was collected by heart puncture with a heparinized syringe. The blood was maintained at $4^{\circ} \mathrm{C}$ and centrifuged at $1,000 \mathrm{~g}$ for $15 \mathrm{~min}$. The plasma and liver were stored at $-80^{\circ} \mathrm{C}$ until analysis.

All procedures were performed in accordance with the Animal Experimentation Guidelines of the Laboratory Animal Care Committee of Seitoku University.

Biochemical assays of plasma and liver: Liver lipids were extracted by the method of Folch et al. [16] Triacylglycerol (TG), total cholesterol (T-cho), and glucose concentrations in plasma and liver extracts were measured using test kits (Triglyceride E-Test Wako, Cholesterol E-Test Wako, Glucose CII-Test Wako), purchased from Wako Pure Chemical Industries, (Osaka, Japan). We also used test kits to assess the activities of leptin (Rat Leptin ELISA Kit, Otsuka Tokyo) in the plasma.

Liver histology: Livers of mice from the three dietary treatment groups were compared histologically. Under deep anesthesia with ether, the chest of each mouse from the three groups was opened rapidly, and the vasculature was perfused with $100 \mathrm{ml}$ of a fixative [4\% paraformaldehyde in $0.01 \mathrm{M}$ sodium phosphate-buffered saline (PBS: $\mathrm{pH}$ 7.4)] at a pressure of $120 \mathrm{mmHg}$ from a 18-gauge cannula inserted into the aorta via an incision in the left ventricle. Immediately after fixative perfusion, the liver was removed, cut into small pieces and immersed in the same fixative for another $2 \mathrm{~h}$ at $4^{\circ} \mathrm{C}$. Then, the liver pieces were washed with PBS, dehydrated in an ascending series of ethanol aqueous solutions $(50 \%, 70 \%, 80 \%, 90 \%$, and $100 \%)$, cleared in xylene, and embedded in paraffin wax. Three $\mu$ m-thick sections made from paraffin-embedded livers were then subjected to hematoxylin and eosin $(\mathrm{H} \& \mathrm{E})$ staining by a routine procedure (Meyer's hematoxylin staining followed by eosin Y staining), and examined under a Keyence BZ900 all-in-one microscope (Keyence, Osaka, Japan).

Statistical analysis: Values are expressed as means \pm SDs. Repeatedmeasures analysis of variance (ANOVA) was used to evaluate the effects of groups. Differences in mean values between groups were tested by Fisher's multiple-range test. p-values less than 0.05 were considered statistically significant.

\section{Results}

Food intake, body and liver weights. The food intake of the HD and HLD groups were much lower than that in the CD group $(p<0.05)$ (Table 2). However, there was no significant difference in the food intake between the HD and HLD groups. No significant differences in food energy intake, final body and liver weight were observed among the three groups. The perirenal fat tissue weight of the HD and HLD groups were higher than that in CD group $(p<0.05)$.

Table 2: Food Intake, Total Energy Intake, Body Weight, Liver and Perirenal Fat Tissue Weights.

\begin{tabular}{|l|l|l|l|}
\hline Group & $\mathrm{CD}^{1}$ & $\mathrm{HD}^{2}$ & $\mathrm{HLD}^{3}$ \\
\hline Food intake (g) & $242 \pm 19.6^{\mathrm{a}}$ & $178 \pm 13.5^{\mathrm{b}}$ & $193 \pm 36.8^{\mathrm{b}}$ \\
\hline $\begin{array}{l}\text { Total energy intake } \\
\text { (Kcal) }\end{array}$ & $871 \pm 70.6$ & $926 \pm 70.2$ & $1006 \pm 191$ \\
\hline $\begin{array}{l}\text { Total energy intake } \\
\text { (Kcal/day) }\end{array}$ & $12.4 \pm 1.01$ & $13.2 \pm 1.00$ & $14.4 \pm 2.74$ \\
\hline Final body weight (g) & $31.2 \pm 2.24$ & $32.2 \pm 3.39$ & $32.2 \pm 1.95$ \\
\hline $\begin{array}{l}\text { Liver weight (g/100g } \\
\text { B.W.) }\end{array}$ & $4.32 \pm 0.28$ & $4.16 \pm 1.18$ & $3.93 \pm 0.35$ \\
\hline $\begin{array}{l}\text { Perienal fat tissue } \\
\text { weight (g/100g B.W.) } \\
\text { Plasma lipids }\end{array}$ & $1.06 \pm 0.20^{\mathrm{b}}$ & $1.69 \pm 0.31^{\mathrm{a}}$ & $1.58 \pm 0.17^{\mathrm{a}}$ \\
\hline Triacylglycerol (mg/dL) & $105 \pm 46.6^{\mathrm{b}}$ & $246 \pm 107^{\mathrm{a}}$ & $143 \pm 46.5^{\mathrm{b}}$ \\
\hline T-Cholesterol (mg/dL) & $75.1 \pm 4.85$ & $80.9 \pm 9.32$ & $82.3 \pm 5.34$ \\
\hline
\end{tabular}

${ }^{1} \mathrm{CD}$ : control diet; ${ }^{2} \mathrm{HD}$ : high-fat diet; ${ }^{3} \mathrm{HLD}:$ Lb. paracasei in a high-fat diet

Values represent means $\pm S D, n=5$. Within a row, values not sharing a common superscript letter are significantly different at $\mathrm{p}<0.05$.

T-Cholesterol, total cholesterol.

Plasma lipid profiles. During the dietary treatment period, no significant differences in plasma T-cholesterol concentration were observed among the three groups (Table 2). The plasma TG of the CD and HLD group were lower than that of the HD group $(\mathrm{p}<0.05)$. The plasma glucose and leptin levels of the CD and HLD groups were lower than those of the HD group $(\mathrm{p}<0.05)$ (Figure 1).

Liver histology and liver lipids. Panels stained with H\&E are shown at $600 \times$ in Figure 2. The micrograph of the liver tissue sections shows that many massive lipid droplets were present in the HD group hepatic cells, with fewer and smaller lipid droplets in the HLD group. 
Citation: Komatsuzaki N, Yamada Y, Ueki Y, Shima J, Morikawa S (2016) Lactobacillus paracasei NFRI 7415 Reduces Liver Lipid Contents in C57BL/6J Mice Fed a High-fat Diet. Int J Clin Nutr Diet 2: 108. doi: http://dx.doi.org/10.15344/ijcnd/2016/108

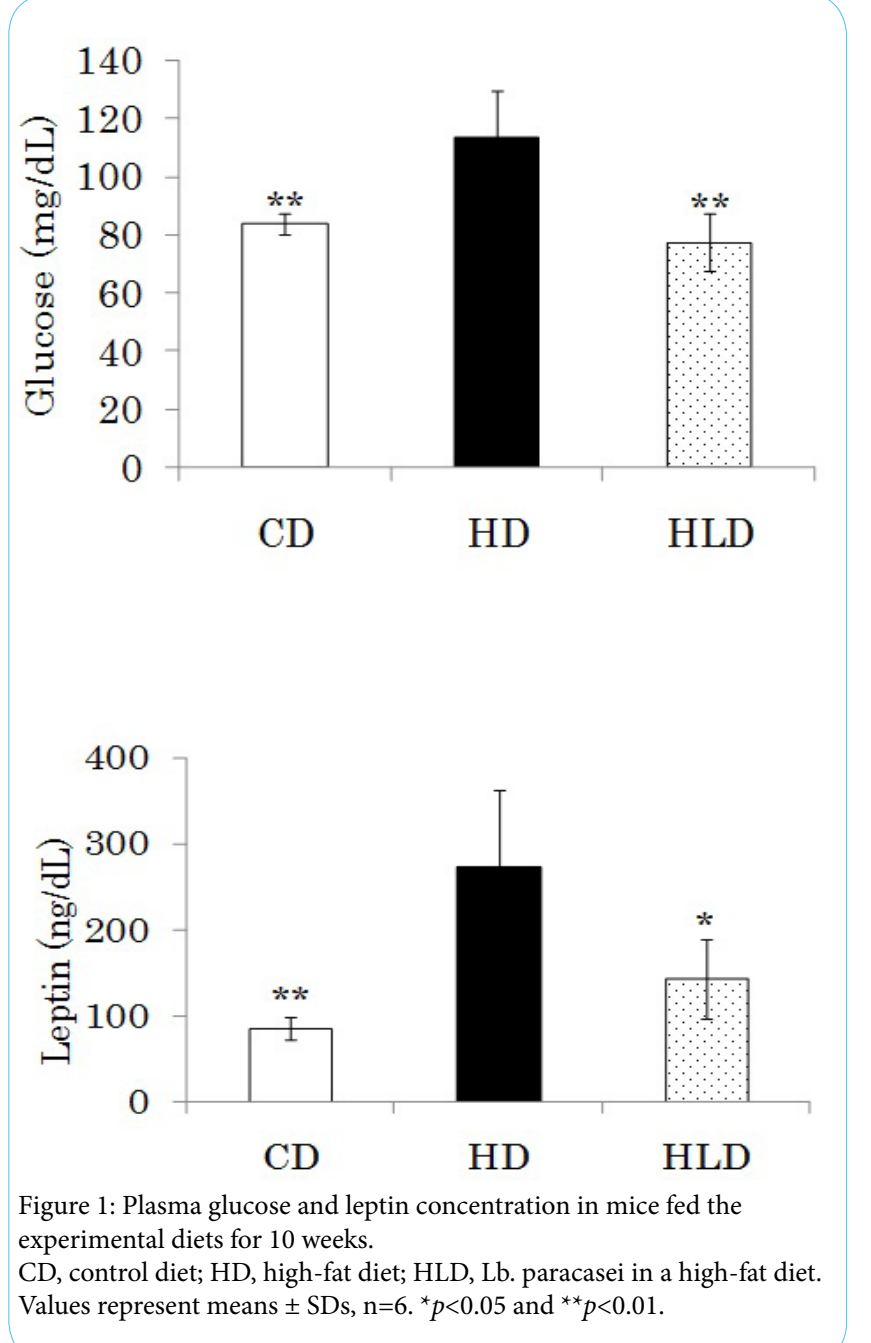

The total lipids of the CD, HD and HLD groups were $85.7 \pm 13.2$ $\mathrm{mg} / \mathrm{g}$, and $129 \pm 23.4 \mathrm{mg} / \mathrm{g}, 100 \pm 8.35 \mathrm{mg} / \mathrm{g}$ liver weight, respectively (Figure 3). Total liver lipids was markedly higher in the HD group than in the CD group $(\mathrm{p}<0.01)$, and total liver lipids of the HLD group was significantly lower than that of the HD group $(\mathrm{p}<0.05)$. The liver TG and T-cho concentrations of the CD and HLD groups were lower those that of the HD group $(\mathrm{p}<0.05)$ (Figure 3).

\section{Discussion}

In the current study, we investigated whether $L b$. paracasei NFRI7415 influences body and fat tissue weight, plasma lipid concentration and hepatic lipid contents in HD-fed C57BL/6J mice. No significant differences in food energy intake, final body and liver weights were observed among the three groups (Table 2). However, the perirenal fat tissue weights of the HD and HLD were higher than that in CD group $(p<0.05)$. The HD and HLD in this study both contained $30.5 \%$ lard and $4.5 \%$ soybean oil (Table 1). Many studies have demonstrated that intake of a high-fat diet tends to lead to a higher body mass index and body fat content than intake of a low-fat diet [17-19]. Excessive intake of animal fat causes increased adipose tissue deposition because perirenal fat-tissue weights are affected by the amount of dietary fat [18] The present results (Table 2) were consistent with those studies.
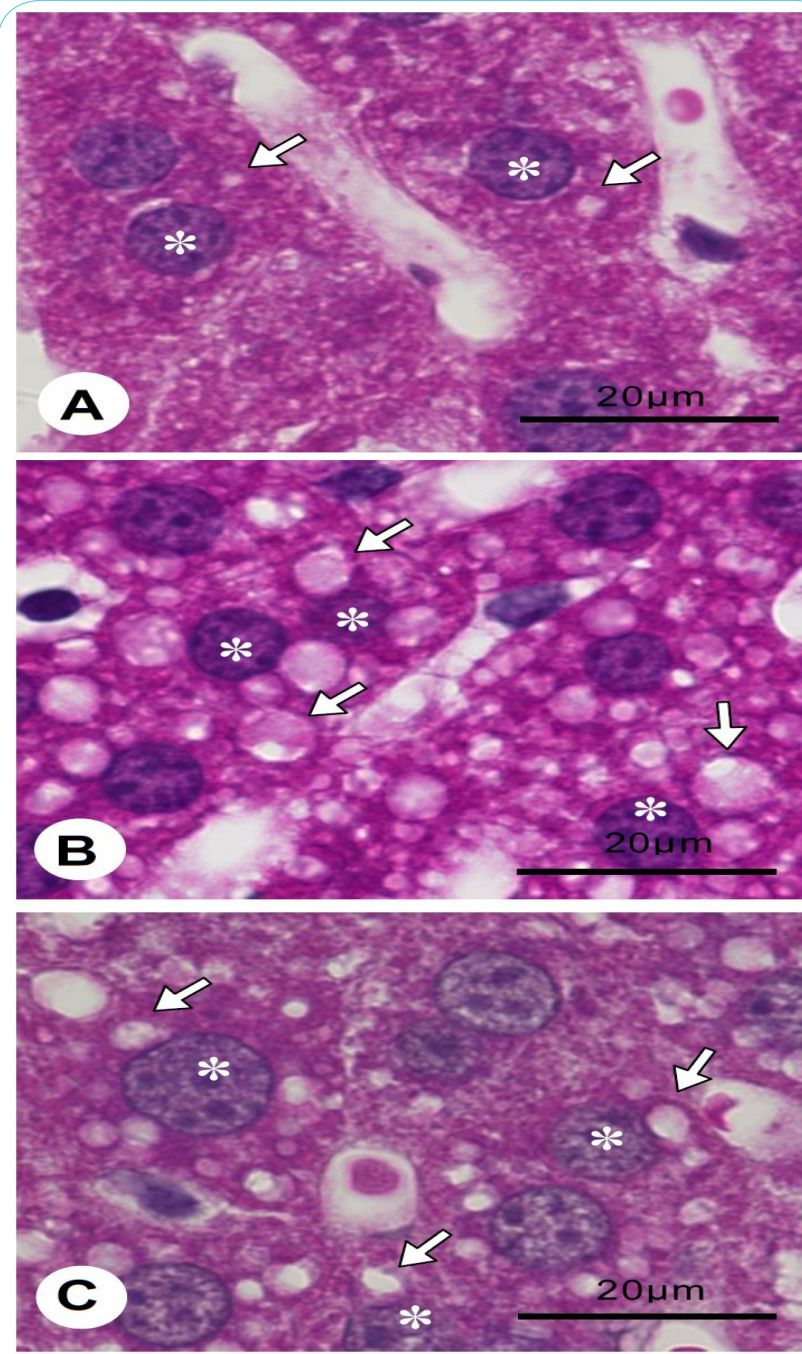

Figure 2: Comparison of the size and number liver lipid droplets (A)-(C) H\&E staining of liver sections.

(A) Liver section from a normal mouse fed with control diet (CD). Lipid droplets (arrows) in hepatocytes (asterisk) are typically small in size (about $2 \mu \mathrm{m}$ in diameter), and a couple of lipid droplets (2-3 pieces) are contained in a cell. SI: Sinusoid. (B) Liver section from a mouse fed with high fat-diet (HD). Lipid droplets (arrows) in hepatocytes (asterisk) are larger than that of normal liver (5-6 $\mu \mathrm{m}$ in diameter). Further, an increased number of droplets in cells (usually 5-7 per cell) is observed. SI: Sinusoid. (C) Liver section from a mouse fed with HD containing $L b$ paracasei. The size of lipid droplets (arrows) in hepatocytes (asterisk) is smaller than that of animals fed HD (about $3 \mu \mathrm{m}$ in diameter). The number of lipid droplets in each hepatocyte is also reduced (usually 2-3 per cell) in comparison to that of animals fed with HD.

Andersson et al. [10] reported the protective effects of a strain of Lactobacillus plantarum on obesity and early diabetes in, to highfat diet (HFD) fed C57BL/6J mice fed a high-fat diet for 20 weeks. Despite L. plantarum decreasing the plasma glucose level in a highfat diet fed mice, the energy intake, body fat content and plasma cholesterol were not different compared to the control group. In other studies, Enterococcus, Lactobacillus and Bifidobacterium were also not observed lower plasma cholesterol in C57BL/6J mice fed a high-fat diet $[2,20]$ In this study, there was no significant difference in the energy intake and plasma T-cho concentration between the HD and HLD groups (Table 2). Therefore, it was supposed that $L b$. paracasei NFRI 7415 did not have an influence on plasma lipids in mice fed 


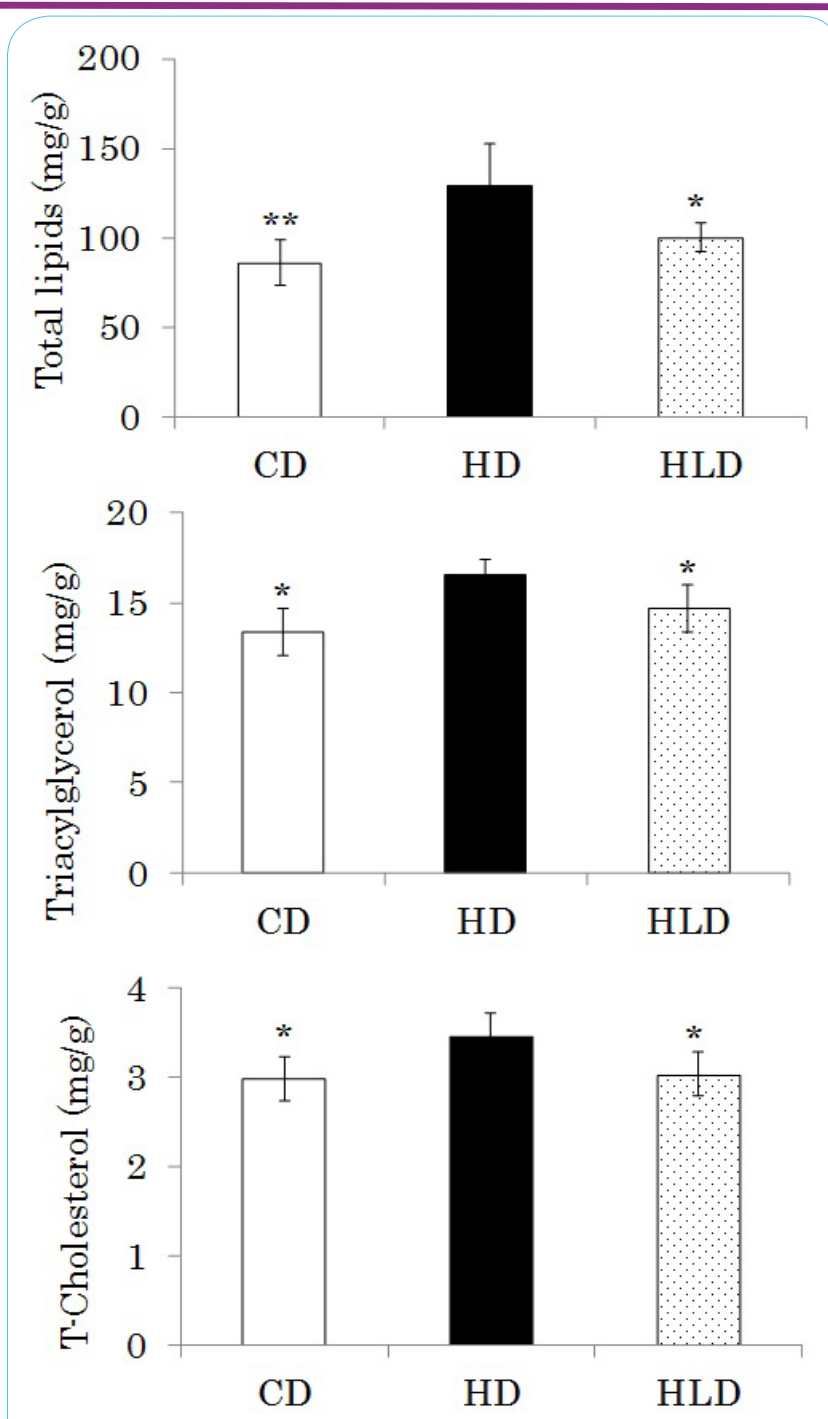

Figure 3: Liver lipids in mice fed the experimental diets for 10 weeks.

CD, control diet; HD, high-fat diet; HLD, Lb. paracasei in a high-fat diet. A) Total lipids; B) Triacylglycerol; C) T-Cholesterol.

Values represent means \pm SDs, $\mathrm{n}=6 .{ }^{*} p<0.05$ and ${ }^{* *} p<0.01$.

T-Cholesterol, total cholesterol.

a high-fat diet. Several studies have indicated that LAB effectively reduced the cholesterol concentration of plasma in animals fed a high-fat diet because LAB enhanced dietary cholesterol excretion into feces by direct cholesterol assimilation [21,22]. Further studies are needed to investigate whether $L b$. paracase $i$ NFRI 7415 can reduce the plasma T-cho concentration in hypercholesterolemia-induced mice.

Leptin is a cytokine hormone secreted by adipocytes. It affects food intake and energy consumption through its receptors in the hypothalamus. Leptin is produced by adipose tissues, and the plasma leptin concentration is linearly related to fat mass and BMI [23-25]. The plasma leptin levels of the CD and HLD group were much lower than that in the HD group (Figure 1). Although no significant differences in the perirenal fat-tissue weight were observed between the HD and HLD groups, the plasma TG of the HLD group was decreased (Table 1). It appears that $L b$. paracase $i$ NFRI 7415 was involved in an obesitypreventing action in mice fed the HLD in this study.
To investigate the effects of $L b$. paracase $i$ NFRI 7415 on the liver in C57BL/6J mice fed the HLD, we measured the liver lipids and the liver histology. Figure 2 shows that the number of liver cells in the HD group was clearly greater than those in the CD and HLD groups. At the same time, the total liver lipids in the CD and HLD group were lower than that of the HD group (Figure 3) $(p<0.05)$. This suggests that intake of $L b$. paracasei NFRI 7415 is effective at preventing hepatic lipid accumulation in a HD setting. The nuclei in the hepatic cells of the HD group appear to be blackened and moribund (Figure 2 ). Heterochromatin is the chromatin structure in the domain, and its gene expression is inhibited [26] In this study, it is supposed that the chromatin in the liver cells of the HD group is in an inactive state. A previous study found that adipose-tissue, expression of the energy consumption gene (lysine-specific demethylase-1) in mice fed a highfat diet was reduced compared with that of mice on a normal diet. [27]. In the future, we need to investigate the gene expression control mechanisms of the liver by excess intake of fat to determine whether intake of $L b$. paracasei NFRI 7415 is involved in the regulation of the lipid metabolism.

Previous studies have reported that $L b$. paracasei NFRI 7415 can remove cholesterol from the plasma and liver of rats fed an ethanol-containing diet [14]. The present study clearly showed that the $L b$. paracasei NFRI 7415 administration reduced hepatic T-cho concentration. The cholesterol-reducing effect by LAB is known to occur through high cholesterol adsorption on the cell body, and increased bile acid adsorption ability [28,29]. Hepatic cholesterol contents have been shown to be significantly lowered by LABs such as Lactobacillus gasseri and Pediococcus pentosaceus [2,30] In another study on rodents fed a high-fat diet, the hepatic cholesterol content was significantly lowered by $P$. pentosaceus, and lipid metabolismrelated genes such as cluster of differentiation 36 (CD36) and stearolCoA desaturase 1 (SCD1) showed decreased expression [2] It is necessary to investigate the effect of this strain on mRNA expression in the liver in mice fed HD. We predict that $L b$. paracasei NFRI 7415 will be shown to have cholesterol adsorption capability ability in the intestinal tract. Further work is in progress to elucidate the mechanism of cholesterol-reducing function of $L b$. paracasei NFRI 7415; specifically, the fecal cholesterol excretion levels of mice treated with this LAB is under investigation.

In conclusion, the present investigation shows that $L b$. paracase NFRI 7415 reduces the content of liver lipids in C57BL/6J mice fed a high-fat diet. Our data suggest that this strain may be effectively applied as a probiotics lactobacillus.

\section{Conflicts of Interests}

The authors have no conflicts of interest to reports.

\section{References}

1. Park KY, Kim B, Hyun CK (2015) Lactobacillus rhamnosus GG improves glucose tolerance through alleviating ER stress and suppressing macrophage activation in db/db mice. J Clin Biochem Nutr 56: 240-246.

2. Zhao X, Higashikawa F, Noda M, Kawamura Y, Matoba Y, et al. (2012) The obesity and fatty liver are reduced by plant-derived Pediococcus pentosaceus LP28 in high fat diet-induced obese mice. PLoS One 7: e30696.

3. Ministry of Health, Labour and Welfare, Japan. (2012) The National Health and Nutrition Survey in Japan. Daiichi Press Tokyo (in Japanese).

4. Manting L, Haihong Z, Jing L, Shaodong C, Yihua L (2011) The model of rat lipid metabolism disorder induced by chronic stress accompanying high-fatdiet. Lipids Health Dis 10: 153. 
Citation: Komatsuzaki N, Yamada Y, Ueki Y, Shima J, Morikawa S (2016) Lactobacillus paracasei NFRI 7415 Reduces Liver Lipid Contents in C57BL/6J Mice Fed a High-fat Diet. Int J Clin Nutr Diet 2: 108. doi: http://dx.doi.org/10.15344/ijcnd/2016/108

Page 5 of 5

5. Xu RY, Wan YP, Fang QY, Lu W, Cai W (2012) Supplementation with probiotics modifies gut flora and attenuates liver fat accumulation in rat nonalcoholic fatty liver disease model. J Clin Biochem Nutr 50: 72-77.

6. Elmadfa I, Klein P, Meyer AL (2010) Immune-stimulating effects of lactic acid bacteria in vivo and in vitro. Proc Nutr Soc 69: 416-420.

7. Kim NH, Moon PD, Kim SJ, Choi IY, An HJ, et al. (2008) Lipid profile lowering effect of Soypro fermented with lactic acid bacteria isolated from Kimchi in high-fat diet-induced obese rats. Biofactors 33: 49-60.

8. Takemura N, Okubo T, Sonoyama K (2010) Lactobacillus plantarum strain No. 14 reduces adipocyte size in mice fed high-fat diet. Exp Biol Med (Maywood) 235: 849-856.

9. Hamad EM, Sato M, Uzu K, Yoshida T, Higashi S, et al. (2009) Milk fermented by Lactobacillus gasseri SBT2055 influences adipocyte size via inhibition of dietary fat absorption in Zucker rats. Br J Nutr 101: 716-724.

10. Andersson U, Bränning C, Ahrné S, Molin G, Alenfall J, et al. (2010) Probiotics lower plasma glucose in the high-fat fed C57BL/6J mouse. Benef Microbes 1: 189-196.

11. Komatsuzaki N, Shima J, Kawamoto S, Momose H, Kimura T (2005) Production of gamma- aminobutyric acid (GABA) by Lactobacillus paracasei isolated from traditional fermented foods. Food Microbiol 22 497-504.

12. Li H, Cao $Y(2010)$ Lactic acid bacterial cell factories for gammaaminobutyric acid. Amino Acids 39: 1107-1116.

13. Jakobs C, Jaeken J, Gibson KM (1993) Inherited disorders of GABA metabolism. J Inherit Metab Dis 16: 704-715.

14. Komatsuzaki N, Shima J (2012) Effects of live Lactobacillus paracasei on plasma lipid concentration in rats fed an ethanol-containing diet. Biosc Biotechnol Biochem 76: 232-237.

15. Reeves PG, Nielsen FH, Fahey GC Jr (1993) AIN-93 purified diets for laboratory rodents: final report of the American Institute of Nutrition ad hoc writing committee on the reformulation of the AIN-76A rodent diet. J Nutr 123: $1939-1951$

16. Folch J, Lees M, Sloane-Stanley GH (1996) A simple method for isolation and purification of total lipids from animal tissues. J Biol Chem 226: 497 509

17. Holmberg S, Thelin A (2013) High dairy fat intake related to less central obesity: a male cohort study with 12 years' follow-up. Scand J Prim Health Care 31: 89-94.

18. Nakashima Y, Yokokura A (2010) Consumption of a high-fat diet containing lard during the growth period in rats predisposes them to favorably respond to the diet in later life. J Nutr Sci Vitaminol (Tokyo) 56: 380-386.

19. Nelson LH, Tucker LA (1996) Diet composition related to body fat in a multivariate study of 203 men. J Am Diet Assoc 96: 771-777.

20. Motonaga C, Kondoh M, Hayashi A, Okamori M, Kitamura Y, et al. (2009) Effect of Enterococcus faecalis FK-23 on anti-obesity in diet-induced obesity mice. Nippon Shokuhin Kagaku Kogaku Kaishi 56: 541-544.

21. Huang Y, Wang X, Wang J, Wu F, Sui Y, et al. (2013) Lactobacillus plantarum strains as potential probiotic cultures with cholesterol-lowering activity. J Dairy Sci 96: 2746-2753.

22. Park YH, Kim JG, Shin YW, Kim SH, Whang KY (2007) Effect of dietary inclusion of Lactobacillus acidophilus ATCC 43121 on cholestero metabolism in rats. J Microbiol Biotechnol 17: 655-662.

23. Sharieh Hosseini SG, Khatamsaz S, Shariati M (2014) The effects of losartan on memory performance and leptin resistance induced by obesity and high-fat diet in adult male rats. Iran J Basic Med Sci 17: 41-48.

24. Vähämiko S, Isolauri E, Laitinen K (2013) Weight status and dietary intake determine serum leptin concentrations in pregnant and lactating women and their infants. Br J Nutr 110: 1098-1106.

25. Frederich RC, Hamann A, Anderson S, Löllmann B, Lowell BB, et al. (1995) Leptin levels reflect body lipid content in mice: evidence for diet-induced resistance to leptin action. Nat Med 1: 1311-1314.

26. Nakayama J (2013) [Heterochromatin assembly and RNA silencing]. Seikagaku 85: 565-570.

27. Hino S, Sakamoto A, Nagaoka K, Anan K, Wang Y, et al. (2012) FAD dependent lysine-specific demethylase-1 regulates cellular energy expenditure. Nat Commun 3: 758.

28. Hung KT, Berisha SZ, Ritchey BM, Santore J, Smith JD (2012) Red blood cells play a role in reverse cholesterol transport. Arterioscler Thromb Vasc Biol 32: 1460-1465.
29. Pigeon RM, Cuesta EP, Gililliand SE (2002) Binding of free bile acids by cells of yogurt starter culture bacteria. J Dairy Sci 85: 2705-2710.

30. Shi L, Li M, Miyazawa K, Li Y, Hiramatsu M, et al. (2013) Effects of heatinactivated Lactobacillus gasseri TMC0356 on metabolic characteristics and immunity of rats with the metabolic syndrome. Br J Nutr 109: 263-272. 